\title{
ASO Visual Abstract: Volume Matters-Longitudinal Retrospective Cohort Study of Outcomes Following Consolidation and Standardization of Adrenal Surgery
}

Reza Rahbari, MD ${ }^{1}$, Mubarika Alavi, MS $^{2}$, Juan F. Alvarez, MD ${ }^{1}$, Carlos A. Perez, MD ${ }^{1}$, Maureen M. Tedesco, MD ${ }^{1}$, Elliot Brill, MD ${ }^{1}$, Judith J. Park, MD ${ }^{1}$, Jonathan Svahn, MD ${ }^{1}$, Elaine U. Yutan, $\mathrm{MD}^{1}$, Arturo G. Martinez, MD ${ }^{1}$, Minhao Zhou, $\mathrm{MD}^{1}$, Scott R. Philipp, $\mathrm{MD}^{1}$, and Lisa J. Herrinton, $\mathbf{P h D}^{2}$

${ }^{1}$ Divison of Adrenal Surgery, Department of Surgery, The Permanente Medical Group, Kaiser Permanente Northern California, Oakland, CA; ${ }^{2}$ Division of Research, Kaiser Permanente Northern California, Oakland, CA

This article (https://doi.org/10.1245/s10434-021-10297-3) describes the implementation of a regionalized care model for adrenal surgery. The program has improved access to high-volume surgeons, decreased operative time and length of hospital stay, and led to same-day adrenal surgery discharges in the majority of patients.

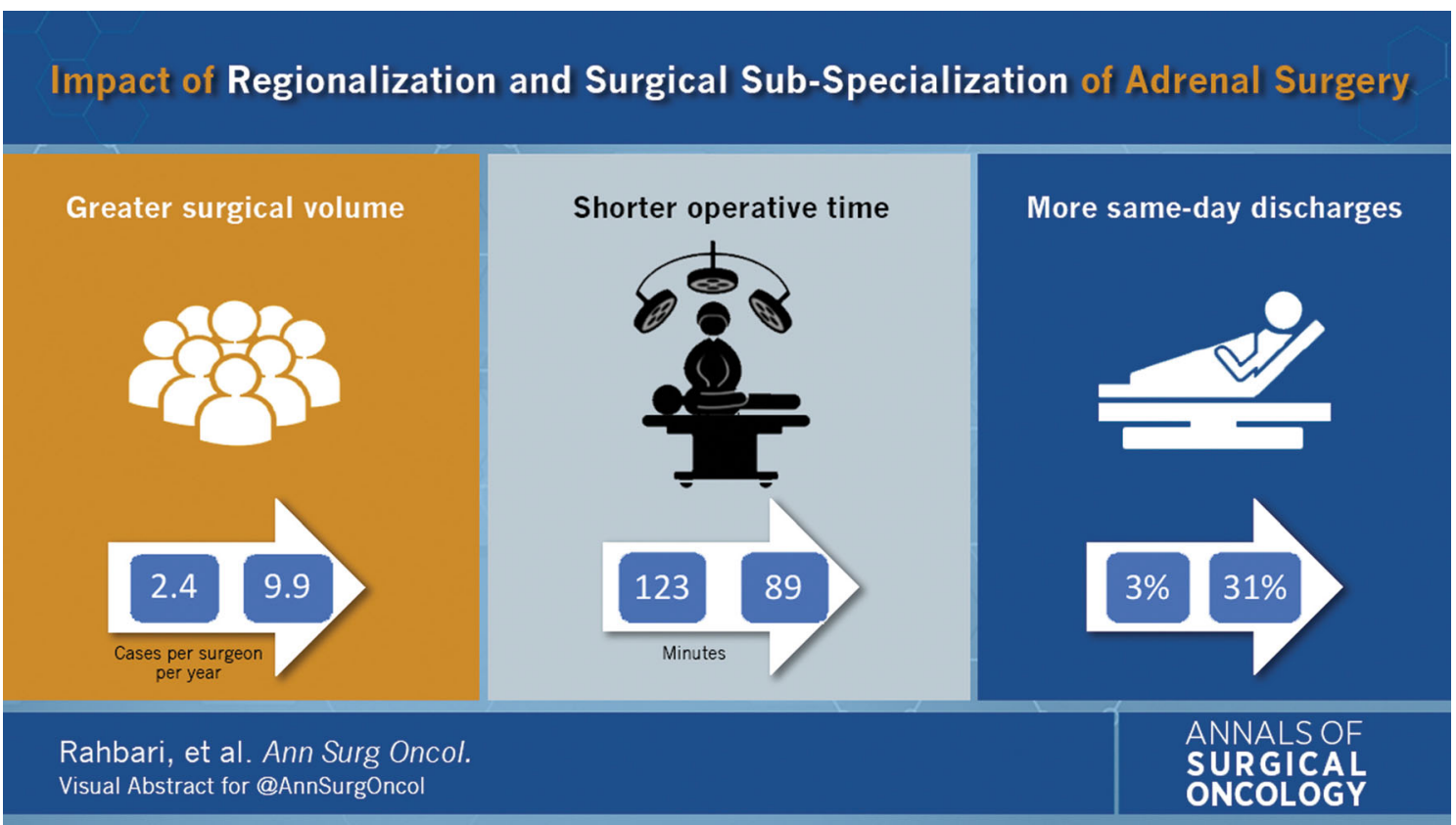

DISCLOSURES This project was supported by The Permanente Medical Group Delivery Science and Applied Research Initiative. The investigators are partners and staff of The Permanente Medical Group and report no other conflicts of interest.

(C) Society of Surgical Oncology 2021, corrected publication 2022

Publisher's Note Springer Nature remains neutral with regard to

R. Rahbari, MD jurisdictional claims in published maps and institutional affiliations. 